Clinical Study

\title{
Gum Arabic (Acacia Senegal) Augmented Total Antioxidant Capacity and Reduced C-Reactive Protein among Haemodialysis Patients in Phase II Trial
}

\author{
Nour Elkhair Ali, ${ }^{1,2}$ Lamis AbdelGadir Kaddam $\mathbb{D}^{1},{ }^{1}$ Suad Yousif Alkarib, ${ }^{3}$ \\ Babikir Gabir Kaballo, ${ }^{2,4}$ Sami Ahmed Khalid, ${ }^{5}$ Abdalazim Higawee, ${ }^{2}$ Alaa AbdElhabib, ${ }^{2}$ \\ Alaa AlaaAldeen, ${ }^{2}$ Aled O. Phillips, ${ }^{6}$ and Amal Mahmoud Saeed ${ }^{7}$ \\ ${ }^{1}$ Department of Physiology, Faculty of Medicine, Alneelain University, Khartoum, Sudan \\ ${ }^{2}$ Nephrology Unit, Military Hospital Omdurman, Sudan \\ ${ }^{3}$ Department of Pharmaceutics, College of Pharmacy, Karary University, Khartoum, Sudan \\ ${ }^{4}$ Department of Medicine, Medicine \& Surgery College, Karary University, Khartoum, Sudan \\ ${ }^{5}$ Faculty of Pharmacy, University of Science \& Technology, Omdurman, Sudan \\ ${ }^{6}$ Institute of Nephrology, Cardiff University School of Medicine, Cardiff, UK \\ ${ }^{7}$ Department of Physiology, Faculty of Medicine, University of Khartoum, Khartoum, Sudan
}

Correspondence should be addressed to Lamis AbdelGadir Kaddam; lamiskaddam@hotmail.com

Received 26 November 2019; Revised 27 January 2020; Accepted 27 February 2020; Published 9 April 2020

Academic Editor: Franca Anglani

Copyright (c) 2020 Nour Elkhair Ali et al. This is an open access article distributed under the Creative Commons Attribution License, which permits unrestricted use, distribution, and reproduction in any medium, provided the original work is properly cited.

\begin{abstract}
Background. Oxidative processes might increase in patients with end-stage renal disease (ESRD) according to the current literature. Oxidative stress (OS) is a risk factor of atherosclerosis and cardiovascular complications, which are major causes of mortality among ESRD patients. Haemodialysis (HD) is life-saving procedure, nevertheless it is an active chronic inflammatory status that could augment cardiovascular disease and increase mortality. Gum Arabic (GA) has been claimed to act as an antioxidant and anti-inflammatory agent in experimental studies and clinical trials. Therefore, we assumed GA supplementation among haemodialysis patients would reduce oxidative stress and consequently reduce the state of chronic inflammatory activation associated with haemodialysis. Methods. Forty end-stage renal failure (ESRF) patients aged 18-80 years who were on regular haemodialysis in Arif Renal Center, Omdurman, Sudan, were recruited. All recruited patients met the inclusion criteria and signed informed consent prior to enrolment. The patients received $30 \mathrm{~g} /$ day of GA for 12 weeks. C-reactive protein (CRP) and complete blood count (CBC) were measured as baseline and monthly. Total antioxidant capacity (TAC) and oxidative stress marker malondialdehyde (MDA) levels were measured before and after GA intake. Ethical approval from the National Medicines and Poisons Board was obtained. Results. Gum Arabic significantly augmented total antioxidant capacity level $(P<0.001)(95 \%$ CI, 0.408-0.625) and also attenuated oxidative marker MDA and C-reactive protein $(P<0.001)$. Conclusions. GA has revealed potent antioxidative and anti-inflammatory properties in haemodialysis patients. Oral digestion of GA (30 g/day) decreased oxidative stress and inflammatory markers among haemodialysis patients. Trial registration. ClinicalTrials.gov Identifier: NCT03214692, registered 11 July 2017 (prospective registration).
\end{abstract}

\section{Introduction}

Oxidative stress results from disparity between systemic manifestation of reactive oxygen species and a body ability either to eradicate reactive intermediates or to repair cellular damage [1]. Due to metabolic process, cells constantly produce free radicals and reactive oxygen species (ROS). The latter are counteracted by the antioxidant defence system composed of enzymatic and nonenzymatic antioxidants, e.g., vitamins A, E, and $\mathrm{C}$ and glutathione [2]. Oxidative stress (OS) has been 
connected to various diseases' pathogenesis, such as renal disease, cardiovascular disease, atherosclerosis, hypertension, cancer, diabetes, and aging $[3,4]$.

OS increased in haemodialysis patients due to deficiency of dietary exogenous antioxidants, accumulation of oxidative products, and drain of antioxidant elements during the dialysis process [5]. All these factors eventually results in the development of chronic inflammation, atherosclerosis, and cardiovascular diseases (CVD) [5]. CVD is the leading cause of mortality among ESRD patients who receive renal replacement therapy $[6,7]$. Hence, these events are responsible cause of death for $34 \%$ of HD patients [7]. Other contributing factors are increased lipid peroxidation and antioxidants exhaustion which increase the risk of atherosclerosis $[6,7]$.

OS has a major role in renal damage; therefore, it is a potential focus for therapeutic strategies [8]. Several attempts are considered to apply oral and/or intravenous antioxidants to attenuate or prevent the inflammatory status, CVD, and the subsequent impact of these events on the mortality. Alphatocopherol, vitamin $\mathrm{C}$, and $\mathrm{N}$-acetylcysteine are considered among the most commonly used antioxidants to counteract OS [8]. Among them, $N$-acetylcysteine seems to be the most efficacious agent [5]. Recently, curcumin was found to attenuate OS among experimental rats with diabetic nephropathy [9].

Gum Arabic (GA) is an Acacia senegal exudate as defined by the FAO/WHO Joint Expert Committee for Food Additives (JECFA) [10]. GA cannot be digested either by humans or by animals [11]. It is a heteropolysaccharide $[12,13]$ and contains minerals like calcium, potassium, and magnesium [14]. In addition, GA has less than 3\% protein and fewer amount of nitrogen [15]. Serine, hydroxyproline, proline, and aspartic acid are the major amino acids present in GA [15]. It is highly water soluble [13] but insoluble in alcohol [16].

Gum Arabic (GA) supplementation has been implicated with its beneficial effect on CKD patients for quite a long time [17]. GA has been used as part of Sudanese traditional medicine to treat chronic renal failure (CRF) long time ago [15]. It seems to have the potential to modify the human physiological status beneficially [15]. Few studies have revealed its positive effect on inflammatory status and oxidative stress in animal models [18] as well as clinical studies involving CKD patients quite recently [19]. GA oral ingestion was associated with a significant reduction in C-reactive protein (CRP) level among CKD patients [19].

In fact, GA considered as prebiotic fibres since oral intake increases serum short-chain fatty acid serum level $[14,20]$. GA has good reputation and promising effects as anticancer [21], antimalarial [22], immune-modulatory [23], and antioxidant $[18,24-26]$ agents.

The protective role of GA against nephrotoxicity includes significant increase in creatinine clearance, suggesting favourable actions in renal insufficiency [27, 28]. The suggested mechanism of action, based on animal studies, is as follows: GA increases nitrogen excretion in faeces and decreases serum urea concentration among CRF patients $[17,28-31]$, subsequently reducing dialysis sessions twice per week instead of three with dramatic positive economic and psychological impact [32]. Previous study from Central
Sudan revealed $50 \mathrm{~g} /$ day of GA supplementation improved biochemical profile of haemodialysis patients [17, 32].

GA decreased MDA and superoxide production significantly and increased GSH and TAC levels among rats with induced nephrotoxicity and CRF [24, 33]. GA antioxidant capacity could be attributed to its amino acids [34]. In 2017, Kaddam et al. reported a novel effect of GA as an antioxidative agent among humans since it increases TAC level and decreases oxidative stress markers among sickle cell anaemic patients [26].

GA beneficial effects may also be intermediated by its immune-modulatory and anti-inflammatory actions $[23,35,36]$. GA modulates immunity in mice [23] through attenuating $\mathrm{TNF} \alpha$ and CRP and increasing anti-inflammatory cytokine IL10 [23, 27, 37]. GA exerted local antiinflammatory effects by modifying nuclear factor- $\kappa \mathrm{B}$ $(\mathrm{NF}-\kappa \mathrm{B})$ on the small intestine [38].

Generalized increase in oxidative stress associated with uraemia has led to the suggestion that antioxidative therapy may have a role in clinical setting [39]. Dietary soluble fibre supplementation can attenuate inflammatory and oxidant status among haemodialysis patients. Dietary fibre supplementation could be one of significant preventative strategies to decrease CVD mortality and morbidity among haemodialysis patients.

To the best of our knowledge, this is the first attempt to address utilization of GA as an antioxidant and anti-inflammatory agent among haemodialysis patients.

\section{Material and Methods}

2.1. Study Subjects. A single-arm nonrandomized open-label clinical trial was conducted among (ESRD) adult patients (their GFR was less than $15 \mathrm{ml} / \mathrm{min} / 1.73 \mathrm{~m}^{2}$ ) on regular HD in Alshaheed Arif Renal Disease Centre in Military Hospital, Khartoum, Sudan. The inclusion criteria were end-stage renal disease patients on regular haemodialysis over three months and aged above 18 years old. The exclusion criteria were as follows: patient known to have ischemic heart disease, pregnant women, patients who had impaired liver function or hepatitis virus or/and HIV positive, and patients currently using Gum Arabic or/and lipid lowering-agents.

2.2. Gum Arabic Administration. GA was provided in powder form by Gum Arabic Company, Khartoum, Sudan. The GA powder was a pure extract produced mechanically from the wildly grown Acacia senegal tree with no additives. Daily dose was 30 gram. The dose was chosen based on earlier studies [26]. GA was packed as $15 \mathrm{~g} / \mathrm{sach}$. Two sachets were to be dissolved in water and consumed early morning on empty stomach. Participants received 56 sachets monthly for twelve weeks. To validate compliance, empty sachets were retained.

\subsection{Measurements}

2.3.1. Sample Collection and Analysis. Blood samples were collected before administering GA after 4, 8, and 12 weeks as 
follows: $2 \mathrm{ml}$ in an EDTA container and $3 \mathrm{ml}$ in a plain container. Serum was separated by centrifugation at $3000 \mathrm{rpm}$ for 15 minutes and stored at $-85^{\circ} \mathrm{C}$. A certified nurse withdrew all blood samples immediately before the dialysis session.

To determine the TAC of the samples, $0.5 \mathrm{ml}$ of $\mathrm{H}_{2} \mathrm{O}_{2}$ was added to $20 \mu \mathrm{l}$ of serum and incubated for $5 \mathrm{~min}$ at $37^{\circ} \mathrm{C}$. The principal of test depends on the reaction of total antioxidants with exogenous hydrogen peroxide $\left(\mathrm{H}_{2} \mathrm{O}_{2}\right)$. The remaining $\mathrm{H}_{2} \mathrm{O}_{2}$ was determined calorimetrically by an enzymatic reaction which included the conversion of 3,5dichloro-2-hydroxybenzenesulfonate to a colored product [40].

MDA level was measured by using thiobarbituric acid reactive species (TBARS) technique [41]. $200 \mu \mathrm{l}$ of serum was mixed well in the test tube with $1 \mathrm{ml}$ of TBA and boiled in boiling water bath $\left(95^{\circ} \mathrm{C}\right)$ for half an hour. The absorbance of sample against blank and standard against distilled water was read at $534 \mathrm{~nm}$ [41].

Quantitative estimation of CRP level was done using MISPA i $i_{2}$ (AGAPPE Diagnostics GmbH, Switzerland) following nephelometry [42]. The reagent composition is CRP R1 (glycine buffer) and CRP R2 latex suspension coated with anti-CRP antibodies (rabbit polyclonal antibody) with the lower detection limit of $0.5 \mathrm{mg} / \mathrm{l}$ (highly sensitive assay). TAC and MDA were measured before and after completion of the trial, while CRP and blood count were measured on monthly basis.

2.4. Statistical Analysis. Data were analyzed using univariate and bivariate analysis using GraphPad prism version 7 . Quantitative data were expressed as mean and standard deviation. Repeated measures analysis of variance (ANOVA) was used to analyze the data recorded monthly. Data were adjusted with Bonferroni correction. We choose paired $T$ test to compare pre- and postintervention results. $P$ value equal to or less than 0.05 was considered significant.

\section{Results}

3.1. Patient Enrolment and Study Duration. We screened all patients who were under regular haemodialysis at Alshaheed Arif Renal Disease Centre, Military Hospital in Khartoum, started on July 2017 aiming for total coverage. We identified 81 patients with ESRD and excluded 39 patients for various reasons (Figure 1). All were Sudanese; 24 were males and 16 females, and their age ranged from 20 to 75 years. The cause of ESRD was unknown for one-third of participants followed by hypertension (Figure 2).

Duration of treatment was twelve weeks except one patient who received GA for ten weeks.

Forty patients presented for follow-up and were included in the final analysis; their baseline characteristics are outlined in Table 1.

Oral Gum Arabic intake significantly augmented the level of TAC (Figure 3) and reduced the levels of both MDA (Figure 4) and CRP (Figure 5). GA significantly increased haemoglobin level and RBC count (Table 2).

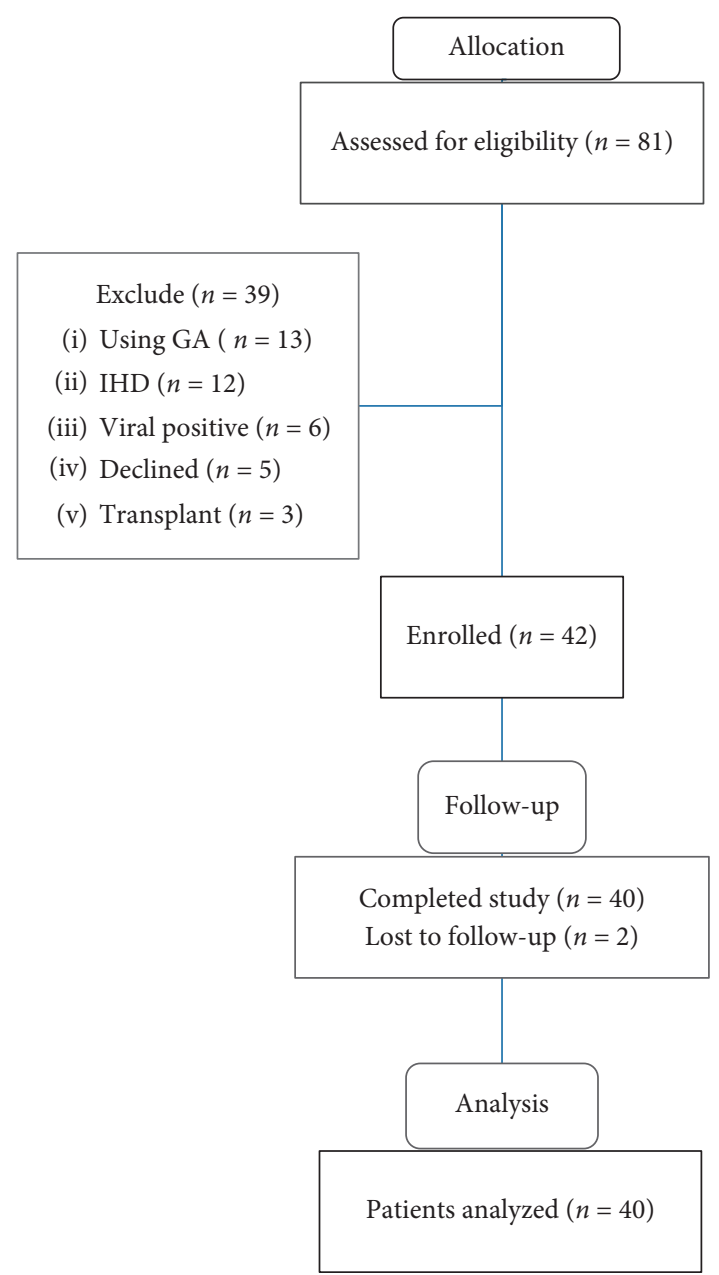

Figure 1: Patients' recruitment and allocation in the clinical trial.

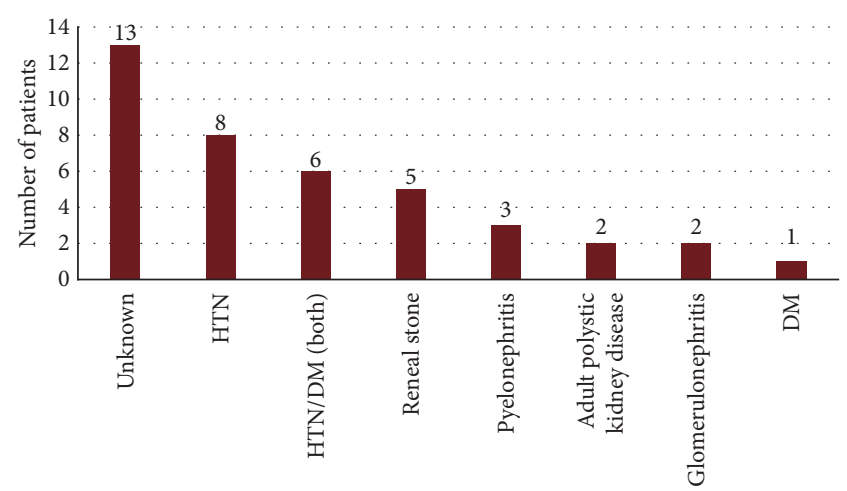

FIGURE 2: Causes of ESRD among study population. HTN, hypertension; DM, diabetes mellitus.

TABLE 1: Baseline characteristics of the study population $(n=40)$.

\begin{tabular}{lc}
\hline Parameter & Mean \pm SD \\
\hline Age (years) & $45.5 \pm 17.22$ \\
Sex (M/F) & $26 / 14$ \\
Dialysis duration (months) & $59.7 \pm 38.38$ \\
Wight (kg) & $57.94 \pm 14.34$ \\
\hline
\end{tabular}




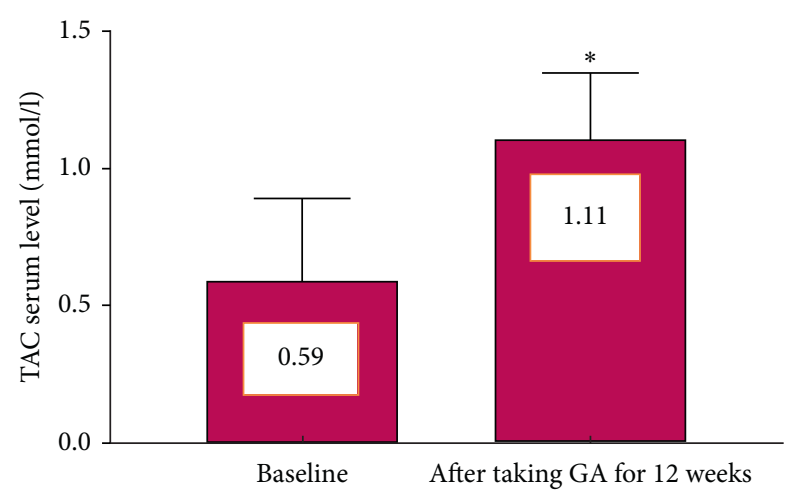

Figure 3: Effect of GA intake on TAC level $(P<0.001)$. Bars represent mean \pm SD. ${ }^{*}$ Significant difference from baseline.



Figure 4: Effect of GA intake on MDA level $(P<0.001)$. Bars represent mean \pm SD. * Significant difference from baseline.

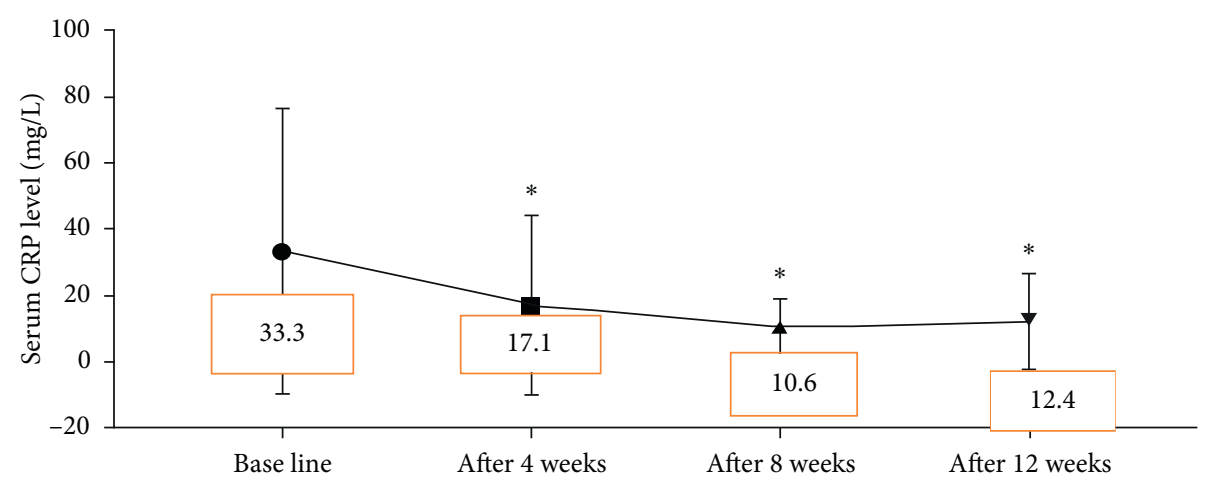

FIgURE 5: Effect of GA intake on CRP level $(P<0.001) .{ }^{*}$ Significant difference from baseline.

TABle 2: Effect of Gum Arabic on blood parameters.

\begin{tabular}{lccccc}
\hline Parameter & Baseline level, mean \pm SD & After 4 weeks, mean \pm SD & After 8 weeks, mean \pm SD & After12 weeks, mean \pm SD $\begin{array}{c}P \text { value, } \\
\text { mean } \pm \text { SD }\end{array}$ \\
\hline $\mathrm{Hb}$ & $8.8 \pm 2$ & $8.2 \pm 1.9$ & $8.785 \pm 1.69$ & $9.541 \pm 1.97$ \\
$\mathrm{MCV}$ & $85.85 \pm 5.35$ & $83.34 \pm 13.58$ & $85.55 \pm 5.369$ & $86.05 \pm 5.27$ \\
$\mathrm{MCHC}$ & $31.89 \pm 1.24$ & $32 \pm 1.4$ & $31.6 \pm 1.2$ & $31.4 \pm 1.2$ & $0.457^{*}$ \\
$\mathrm{MCH}$ & $27.39 \pm 2.12$ & $27.34 \pm 2.249$ & $27.05 \pm 2.2$ & 0.1598 \\
$\mathrm{WBCs}$ & $5.256 \pm 1.962$ & $5.497 \pm 2.266$ & $5.241 \pm 2.09$ & $5.869 \pm 2.11$ \\
RBCs & $3.206 \pm 0.83$ & $2.998 \pm 0.7267$ & $3.237 \pm 0.669$ & $3.5 \pm 0.67$ & 0.8492 \\
Platelets & $181 \pm 70.51$ & $163.6 \pm 58.99$ & $187.5 \pm 82.29$ & 0.5916 \\
\hline
\end{tabular}


3.2. GA Tolerance and Side Effects. More than $50 \%$ of patients reported gastrointestinal symptoms such as bloating, diarrhoea, nausea, and vomiting. All these symptoms resolved spontaneously within the first two weeks. Compliance to GA was excellent, evidenced by follow-up and the retained number of empty sachets.

\section{Discussion}

Renal replacement therapy (haemodialysis) in end-stage renal disease (ESRD) is associated with amplified oxidative stress which involves in the pathogenesis of kidney failure events, systemic complications, and subsequently cardiovascular diseases $[6,8]$. MDA and free radicals production increased in inflammatory kidney diseases including ESRD $[4,5]$. Based on recent researches, OS may be mediated by myeloperoxidase (MPO), and the latter may have a role in development of cardiovascular complications in dialysis patients [6]. Moreover, dialysis treatment per se exaggerates OS [5]. Therefore, this study was designed to determine the effect of GA on malondialdehyde (MDA), which is considered as a marker of oxidative stress among ESRD patients on regular HD. Biomarkers of oxidative stress are altered in uremic patients [39]. These alterations include concentration of lipid peroxidation products, mainly MDA, which was found to be higher in uremic patients compared to healthy people [39, 43].

Results of this interventional clinical trial provided first clinical evidence to consolidate the effect of GA on oxidative stress and inflammatory status among haemodialysis patients. The results revealed that Gum Arabic supplementation for 12 weeks increased serum concentration of total antioxidant capacity (TAC) (Figure 3). Postsupplementation values of blood MDA content, which is a marker for oxidant substances released by dialysis, were significantly lowered compared to baseline values $(P<0.001)$ (Figure 4$)$. GA significantly decreased MDA level in the CRF animal model and nephrotoxicity $[18,24]$. An experimental study showed that Gum Arabic significantly reduced OS in sickle cell anemia patients [26].

In addition, we evaluated Gum Arabic's effect on inflammatory status in haemodialysis patients and found that CRP was significantly reduced on monthly basis (Figure 5). Haemodialysis is considered as an inflammatory state $[44,45]$ and causes of inflammation are multifactorial including blood exposure to dialyzer membranes or tubing, vascular access's infections, reduced antioxidants, and increased oxidative stress [46]. Alamin et al.'s study revealed that 10-40 gram/day of GA significantly reduced CRP level among CKD patients [19]. Recent research reported comparable results to our finding and stated that dietary soluble fibre can counteract inflammatory and malnutrition status among haemodialysis patients [47]. An early study showed GA significantly decreased TNFa level and ESR among rheumatoid patients [36].

There was significant increase in both haemoglobin concentration and RBC count in our study population (Table 2), which may attribute partially to regular administration of erythropoietin injection during the last 4 weeks. On the other hand, GA may increase the response to erythropoietin injection due to diminished CRP level.
Inflammation is one of the major causes of resistance to erythropoietin (EPO) treatment [48]. No significant change on other blood indices, MCV and $\mathrm{MCH}$, was detected. By contrast, a previous study indicated that GA intake increases MCV [49]. There was no significant difference in platelet count and TWBC. Similar results were recorded among sickle cell anemia and rheumatoid patients where GA revealed no effect on reticulocytes, RBCs, and platelets with insignificant decrease in WBCs [36, 49]. An early study conducted among healthy volunteers found that there is no influence of GA in blood indices [13].

Our results revealed promising outcome of GA supplementation among haemodialysis patients, manifested by significant decrease in oxidative stress and inflammatory markers, both considered as risk factors for atherosclerosis and cardiovascular diseases. In resource-limited settings, where patients have limited access to renal transplantation and relay mainly on dialysis for years to keep alive (Table 1), causes of ERSD were not recognized (Figure 2). GA could be utilized safely to ameliorate oxidative stress and inflammation induced by haemodialysis and renal disease itself. Nevertheless, testing the effect of GA on morbidity and mortality and development of atherosclerosis and ischemic heart diseases, longer and multiarm trials should be conducted to overcome current limitations such as small sample size and short period of intervention.

\section{Conclusions}

The present study revealed that GA intake significantly elevated TAC and inversely decreased MDA levels coupled with significant and concurrent decrease in CRP. In addition, GA increased haemoglobin level and RBC count significantly without substantial effect on other blood parameters.

\section{Abbreviations \\ CKD: Chronic kidney disease \\ CRF: Chronic renal failure \\ CRP: C-reactive protein \\ CVD: Cardiovascular disease \\ EPO: Erythropoietin \\ ESRD: End-stage renal disease \\ GA: Gum Arabic \\ HD: Haemodialysis \\ MDA: Malondyaldeide \\ OS: $\quad$ Oxidative stress \\ ROS: Reactive oxygen species \\ RRt: Renal replacement therapy \\ TAC: Total antioxidant capacity \\ TNF $\alpha$ : Tumor necrosis factor $\alpha$ \\ TWBCs: Total white blood cells.}

\section{Data Availability}

The datasets used and/or analyzed during the current study are available from the corresponding author upon reasonable request. 


\section{Consent}

The principal investigator obtained informed consent from each participant to publish the data without breaching confidentiality.

\section{Disclosure}

The study was presented earlier as proceeding abstract in Europhysiology in 2018.

\section{Conflicts of Interest}

The authors declare no conflicts of interest.

\section{Authors' Contributions}

NE and LK participated in the study design. NE, LK, SY, and AS were involved in all aspects of the study conduct. NE, LK, $\mathrm{SK}, \mathrm{AO}$, and $\mathrm{AS}$ participated in the writing and reviewing of the manuscript. NE and LK analyzed data. NE and AM performed laboratory studies. $\mathrm{AAB}, \mathrm{AA}$, and $\mathrm{BG}$ were significant clinical contributors to the study. All authors approved final version of manuscript.

\section{Acknowledgments}

The authors would like to thank Gum Arabic Board, Khartoum, Sudan, for providing gum Arabic and the staff at Arif Renal Centre for their kind collaboration in data collection and laboratory analysis of samples. Supporting fund was obtained from Alneelain University, Sudan (to principal investigator NE), and from Gum Arabic Board (to SA).

\section{References}

[1] B. Halliwell and C. E. Cross, "Oxygen-derived species: their relation to human disease and environmental stress," Environmental Health Perspectives, vol. 102, no. 10, pp. 5-12, 1994.

[2] M. L. Urso and P. M. Clarkson, "Oxidative stress, exercise, and antioxidant supplementation," Toxicology, vol. 189, no. 1-2, pp. 41-54, 2003.

[3] E. Schleicher and U. Friess, "Oxidative stress, AGE, and atherosclerosis," Kidney International, vol. 72, pp. S17-S26, 2007.

[4] R. Agarwal, N. Vasavada, N. G. Sachs, and S. Chase, "Oxidative stress and renal injury with intravenous iron in patients with chronic kidney disease," Kidney International, vol. 65, no. 6, pp. 2279-2289, 2004.

[5] V. Liakopoulos, S. Roumeliotis, X. Gorny, E. Dounousi, and P. R. Mertens, "Oxidative stress in hemodialysis patients: a review of the literature," Oxidative Medicine And Cellular Longevity, vol. 2017, Article ID 3081856, 22 pages, 2017.

[6] E. O. Gosmanova and N.-A. Le, "Cardiovascular complications in CKD patients: role of oxidative stress," Cardiology Research and Practice, vol. 2011, Article ID 156326, 8 pages, 2011.

[7] P. Jackson, C. M. Loughrey, J. H. Lightbody, P. T. McNamee, and I. S. Young, "Effect of hemodialysis on total antioxidant capacity and serum antioxidants in patients with chronic renal failure," Clinical Chemistry, vol. 41, no. 8, pp. 1135-1138, 1995.
[8] J. S. Coombes and R. G. Fassett, "Antioxidant therapy in hemodialysis patients: a systematic review," Kidney International, vol. 81, no. 3, pp. 233-246, 2012.

[9] S. Asadi, M. T. Goodarzi, J. Karimi, M. Hashemnia, and I. Khodadadi, "Does curcumin or metformin attenuate oxidative stress and diabetic nephropathy in rats?" Journal of Nephropathology, vol. 8, no. 1, 2019.

[10] G. O. Phillips, T. Ogasawara, and K. Ushida, "The regulatory and scientific approach to defining gum arabic (Acacia senegal and Acacia seyal) as a dietary fibre," Food Hydrocolloids, vol. 22, no. 1, pp. 24-35, 2008.

[11] J. Adiotomre, M. A. Eastwood, C. A. Edwards, and W. G. Brydon, "Dietary fiber: in vitro methods that anticipate nutrition and metabolic activity in humans," The American Journal of Clinical Nutrition, vol. 52, no. 1, pp. 128-134, 1990.

[12] D. M. W. Anderson and J. F. Stoddart, "Studies on uronic acid materials," Carbohydrate Research, vol. 2, no. 2, pp. 104-114, 1966.

[13] A. H. M. Ross, M. A. Eastwood, W. G. Brydon, J. R. Anderson, and D. M. W. Anderson, "A study of the effects of dietary gum arabic in humans," The American Journal of Clinical Nutrition, vol. 37, no. 3, pp. 368-375, 1983.

[14] W. Calame, A. R. Weseler, C. Viebke, C. Flynn, and A. D. Siemensma, "Gum arabic establishes prebiotic functionality in healthy human volunteers in a dose-dependent manner," British Journal of Nutrition, vol. 100, no. 6, pp. 1269-1275, 2008.

[15] B. H. Ali, A. Ziada, and G. Blunden, "Biological effects of gum arabic: a review of some recent research," Food and Chemical Toxicology, vol. 47, no. 1, pp. 1-8, 2009.

[16] W. Johnson, "Final report of the safety assessment of Acacia catechu gum, Acacia concinna fruit extract, Acacia dealbata leaf extract, Acacia dealbata leaf wax, Acacia decurrens extract, Acacia farnesiana extract, Acacia farnesiana flower wax, Acacia farnesiana gum, Acacia senegal extract, Acacia senegal gum, and Acacia senegal gum extract," International Journal of Toxicology, vol. 24, pp. 75-118, 2005.

[17] S. A. Khalid, A. M. Musa, A. M. Saeed et al., "Manipulating dietary fibre: gum arabic making friends of the colon and the kidney," Bioactive Carbohydrates and Dietary Fibre, vol. 3, no. 2, pp. 71-76, 2014.

[18] B. H. Ali, I. Al-Husseni, S. Beegam, A. Al-Shukaili, A. Nemmar, and S. Schierling, "Effect of gum Arabic on oxidative stress and inflammation in adenine-induced chronic renal failure in rats," PloS One, vol. 8, no. 2, 2013.

[19] S. Elamin, M. J. Alkhawaja, A. Y. Bukhamsin, M. A. Idris, M. M. Abdelrahman, and N. K. Abutaleb, "Gum Arabic reduces C-reactive protein in chronic kidney disease patients without affecting urea or indoxyl sulfate levels," International Journal of Nephrology, vol. 2017, Article ID 9501470, 6 pages, 2017.

[20] R. Babiker, T. H. Merghani, K. Elmusharaf, R. M. Badi, F. Lang, and A. M. Saeed, "Effects of gum Arabic ingestion on body mass index and body fat percentage in healthy adult females: two-arm randomized, placebo controlled, doubleblind trial," Nutrition Journal, vol. 11, no. 1, p. 111, 2012

[21] O. Nasir, K. Wang, M. Föller et al., "Downregulation of angiogenin transcript levels and inhibition of colonic carcinoma by gum Arabic (Acacia senegal)," Nutrition and Cancer, vol. 62, no. 6, pp. 802-810, 2010.

[22] A. Ballal, D. Bobbala, S. M. Qadri et al., "Anti-malarial effect of gum arabic,” Malaria Journal, vol. 10, no. 1, p. 139, 2011.

[23] N. T. Xuan, E. Shumilina, O. Nasir, D. Bobbala, F. Götz, and F. Lang, "Stimulation of mouse dendritic cells by gum 
Arabic," Cellular Physiology and Biochemistry, vol. 25, no. 6, pp. 641-648, 2010.

[24] A. A. Al-Majed, A. R. Abd-Allah, A. C. Al-Rikabi, O. A. AlShabanah, and A. M. Mostafa, "Effect of oral administration of Arabic gum on cisplatin-induced nephrotoxicity in rats," Journal of Biochemical and Molecular Toxicology, vol. 17, no. 3, pp. 146-153, 2003.

[25] A. A. Al-Yahya, A. A. Al-Majed, A. M. Gado et al., "Acacia senegal gum exudate offers protection against cyclophosphamide-induced urinary bladder cytotoxicity," Oxidative Medicine and Cellular Longevity, vol. 2, no. 4, pp. 207-213, 2009.

[26] L. Kaddam, I. Fadl-Elmula, O. A. Eisawi, H. A. Abdelrazig, M. A. Salih, and F. Lang, "Gum Arabic as novel anti-oxidant agent in sickle cell anemia, phase II trial," BMC Hematology, vol. 17, no. 1, p. 4, 2017.

[27] B. H. Ali, S. Beegam, I. Al-Lawati, M. I. Waly, M. Al Za'abi, and A. Nemmar, "Comparative efficacy of three brands of gum acacia on adenine-induced chronic renal failure in rats," Physiological Research, vol. 62, no. 62, pp. 47-56, 2013.

[28] O. Nasir, F. Artunc, A. Saeed et al., "Effects of gum arabic (Acacia senegal) on water and electrolyte balance in healthy mice," Journal of Renal Nutrition, vol. 18, no. 2, pp. 230-238, 2008.

[29] N. Matsumoto, S. Riley, D. Fraser et al., "Butyrate modulates TGF- $\beta 1$ generation and function: potential renal benefit for Acacia (sen) supergum (gum arabic)?” Kidney International, vol. 69, no. 2, pp. 257-265, 2006.

[30] A. J. Al Mosawi, "The use of acacia gum in end stage renal failure," Journal of Tropical Pediatrics, vol. 53, no. 5, pp. 362-365, 2007.

[31] B. H. Ali, S. Al-Salam, M. Al Za'abi et al., "New model for adenine-induced chronic renal failure in mice, and the effect of gum acacia treatment thereon: comparison with rats," Journal of Pharmacological and Toxicological Methods, vol. 68, no. 3, pp. 384-393, 2013.

[32] A. A. Ali, K. E. Ali, A. E. Fadlalla, and K. E. Khalid, "The effects of gum arabic oral treatment on the metabolic profile of chronic renal failure patients under regular haemodialysis in central Sudan," Natural Product Research, vol. 22, no. 1, pp. 12-21, 2008.

[33] B. H. Ali, S. Al-Salam, I. Al Husseni et al., "Effects of gum Arabic in rats with adenine-induced chronic renal failure," Experimental Biology and Medicine, vol. 235, no. 3, pp. 373382, 2010.

[34] E. Rodrigues, L. R. B. Mariutti, A. F. Faria, and A. Z. Mercadante, "Microcapsules containing antioxidant molecules as scavengers of reactive oxygen and nitrogen species," Food Chemistry, vol. 134, no. 2, pp. 704-711, 2012.

[35] B. H. Ali, A. Ziada, I. Al Husseni, S. Beegam, and A. Nemmar, "Motor and behavioral changes in rats with adenine-induced chronic renal failure: influence of acacia gum treatment," Experimental Biology and Medicine, vol. 236, no. 1, pp. 107112, 2011.

[36] E. Kamal, L. A. Kaddam, M. Dahawi et al., "Gum arabic fibers decreased inflammatory markers and disease severity score among rheumatoid arthritis patients, phase II Trial," International Journal of Rheumatology, vol. 2018, Article ID 4197537, 6 pages, 2018.

[37] K. Ushida, H. Hatanaka, R. Inoue, T. Tsukahara, and G. O. Phillips, "Effect of long term ingestion of gum arabic on the adipose tissues of female mice," Food Hydrocolloids, vol. 25, no. 5, pp. 1344-1349, 2011.
[38] R. A. Wapnir, B. Sherry, C. N. Codipilly, L. O. Goodwin, and I. Vancurova, "Modulation of rat intestinal nuclear factor NF$\kappa \mathrm{B}$ by gum arabic," Digestive Diseases and Sciences, vol. 53, no. 1, pp. 80-87, 2008.

[39] J. Himmelfarb and R. M. Hakim, "Oxidative stress in uremia," Current Opinion in Nephrology and Hypertension, vol. 12, no. 6, pp. 593-598, 2003.

[40] D. Koracevic, G. Koracevic, V. Djordjevic, S. Andrejevic, and V. Cosic, "Method for the measurement of antioxidant activity in human fluids," Journal of Clinical Pathology, vol. 54, no. 5, pp. 356-361, 2001.

[41] S. Kei, "Serum lipid peroxide in cerebrovascular disorders determined by a new colorimetric method," Clinica Chimica Acta, vol. 90, no. 1, pp. 37-43, 1978.

[42] P. L. Tugirimana, A. L. Holderbeke, J. A. Kint, and J. R. Delanghe, "A new turbidimetric method for assaying serum C-reactive protein based on phosphocholine interaction," Clinical Chemistry and Laboratory Medicine, vol. 47, no. 11, pp. 1417-1422, 2009.

[43] J. Himmelfarb, "Oxidative stress in hemodialysis," in $\mathrm{He}$ modialysis-From Basic Research to Clinical Trials. 161, pp. 132-137, Karger Publishers, Basel, Switzerland, 2008.

[44] C. Zoccali, F. A. Benedetto, F. Mallamaci et al., "Inflammation is associated with carotid atherosclerosis in dialysis patients," Journal of Hypertension, vol. 18, no. 9, pp. 1207-1213, 2000.

[45] J. Zimmermann, S. Herrlinger, A. Pruy, T. Metzger, and C. Wanner, "Inflammation enhances cardiovascular risk and mortality in hemodialysis patients," Kidney International, vol. 55 , no. 2, pp. 648-658, 1999.

[46] P. Stenvinkel, "Inflammation in end-stage renal failure: could it be treated?" Nephrology Dialysis Transplantation, vol. 17, no. 8, pp. 33-38, 2002.

[47] L. M. Xie, Y. Y. Ge, X. Huang, Y. Q. Zhang, and J. X. Li, "Effects of fermentable dietary fiber supplementation on oxidative and inflammatory status in hemodialysis patients," International Journal of Clinical and Experimental Medicine, vol. 8, no. 8, pp. 1363-9, 2015.

[48] P. Bárány, J. Divino Filho, and J. Bergström, "High C-reactive protein is a strong predictor of resistance to erythropoietin in hemodialysis patients," American Journal of Kidney Diseases, vol. 29, no. 4, pp. 565-568, 1997.

[49] L. Kaddam, I. FdleAlmula, O. A. Eisawi, H. A. Abdelrazig, M. Elnimeiri, and F. Lang, "Gum Arabic as fetal hemoglobin inducing agent in sickle cell anemia; in vivo study," BMC Hematology, vol. 15, no. 1, p. 19, 2015. 